\title{
Core Cross-linked Star Polymers for Temperature/pH Controlled Delivery of 5-Fluorouracil
}

\author{
Elizabeth Sánchez-Bustos, ${ }^{1,2}$ José M. Cornejo-Bravo, ${ }^{2}$ and Angel Licea-Claverie ${ }^{1}$ \\ ${ }^{1}$ Instituto Tecnológico de Tijuana, Centro de Graduados e Investigación en Química, Apartado Postal 1166, 22000 Tijuana, BC, Mexico \\ ${ }^{2}$ Facultad de Ciencias Químicas e Ingeniería, Universidad Autónoma de Baja California, Calzada Universidad 14418, \\ 22390 Tijuana, BC, Mexico
}

Correspondence should be addressed to José M. Cornejo-Bravo; jmcornejo@uabc.edu.mx and Angel Licea-Claverie; aliceac@tectijuana.mx

Received 28 September 2015; Revised 31 December 2015; Accepted 10 January 2016

Academic Editor: Marinos Pitsikalis

Copyright (C) 2016 Elizabeth Sánchez-Bustos et al. This is an open access article distributed under the Creative Commons Attribution License, which permits unrestricted use, distribution, and reproduction in any medium, provided the original work is properly cited.

\begin{abstract}
RAFT polymerization with cross-linking was used to prepare core cross-linked star polymers bearing temperature sensitive arms. The arms consisted of a diblock copolymer containing $N$-isopropylacrylamide (NIPAAm) and 4-methacryloyloxy benzoic acid (4MBA) in the temperature sensitive block and poly(hexyl acrylate) forming the second hydrophobic block, while ethyleneglycol dimethacrylate was used to form the core. The acid comonomer provides $\mathrm{pH}$ sensitivity to the arms and also increases the transition temperature of polyNIPAAm to values in the range of 40 to $46^{\circ} \mathrm{C}$. Light scattering and atomic force microscopy studies suggest that loose core star polymers were obtained. The star polymers were loaded with 5-fluorouracil (5-FU), an anticancer agent, in values of up to $30 \mathrm{w} / \mathrm{w} \%$. In vitro release experiments were performed at different temperatures and $\mathrm{pH}$ values, as well as with heating and cooling temperature cycles. Faster drug release was obtained at $42^{\circ} \mathrm{C}$ or pH 6, compared to normal physiological conditions $\left(37^{\circ} \mathrm{C}\right.$, $\mathrm{pH}$ 7.4). The drug carriers prepared acted as nanopumps changing the release kinetics of 5-FU when temperatures cycles were applied, in contrast with release rates at a constant temperature. The prepared core cross-linked star polymers represent advanced drug delivery vehicles optimized for 5-FU with potential application in cancer treatment.
\end{abstract}

\section{Introduction}

Recent research reports on stimuli-responsive polymers have been focused in the field of polymer topology, particularly in the synthesis of well-defined macromolecules with precisely controlled architecture by incorporating site-specific branching points and functionalities [1], in addition to their ability to respond to various stimuli like temperature, $\mathrm{pH}$, or light [2]. The features mentioned above are desirable for the preparation of tailor-made polymeric systems for a broad range of applications covering the fields of drug delivery, diagnostics, biotechnology, sensors: micromechanical and optical systems, coatings, and textiles [3].

Star polymers represent a special case of branched macromolecules and are very attractive for polymer chemists due to their multiarm topological architecture, smaller hydrodynamic size, ideal rheological behavior, particular bulkiness, and solution properties compared to their linear counterparts [4]. Well-defined star polymers can be prepared by growing the polymer arms from a functional core (core-first) or by the "arm-first" approach, where end-functionalized polymeric chains are attached to a functional core by specific reactions or by copolymerization with a cross-linker. The "arm-first" approach exhibits several advantages over the "core-first" methodology, such as an easier procedure to achieve higher molecular weight star polymers without the formation of coupling star structures [5] and the possibility of having well-defined arms and combining different types of arms in a single star [6]. Star polymers were first synthesized by the "arm-first" approach in 1966 using anionic living polymerization to obtain arms followed by a reaction with a suitable linking agent to create the star polymer architecture [7]. Controlled radical polymerization (CRP) techniques, such as atom transfer radical polymerization (ATRP) [8], 
nitroxide mediated radical polymerization (NMP) [9], and reversible addition-fragmentation chain transfer polymerization (RAFT), have been versatile techniques for the synthesis of star polymers using both "arm-first" and "core-first" methods [10-13]. Star polymers can be divided into two structural categories, homogeneous (homoarm) or mixed (miktoarm) star polymers [6]. Arms may be built of homo-, co-, or even terpolymers, in such a way that the final properties of the resulting star-shaped polymers can be adjusted by choosing the respective chemical structure of arms and core, depending on the required application [14].

Amphiphilic polymers formed by hydrophilic and hydrophobic segments self-aggregate in aqueous solutions to form micelles and other types of aggregates [15-18]. Amphiphilic star polymers may also aggregate in a complex fashion depending on their chemical composition, relative size of core to arms, number of arms, and so forth [19-21].

Due to their small size $(<200 \mathrm{~nm})$, star polymers may accumulate in tumors or inflamed tissues through the enhanced permeability and retention effect (EPR) [22]. Several pathologies, such as inflammation, tumor, and infarcted tissue, show a local decrease in $\mathrm{pH}$ (1-2.5 pH units) [2325]. The particular $\mathrm{pH}$ conditions at pathological sites, and also local heating by $2-5^{\circ} \mathrm{C}$ in solid tumors, can be used to enhance drug release from accumulated or locally administered stimuli-responsive polymeric materials [26-28].

An important issue for the biomedical application of temperature sensitive stars polymers is to adjust the transition temperature (LCST) above normal body temperature; thus, when the nanomaterials are injected into the body, they are in the swollen state $\left(37^{\circ} \mathrm{C}<\right.$ LCST) and circulate in blood vessels but collapse inside cancer tissue ( $T_{\text {tumor }}>$ LCST) due to the hydrophobic change at temperatures above their LCST [29]. The process of collapse (and possible aggregation) leads to drug release inside tumors [30,31]. The LCST of polyNIPAAm $\left(32^{\circ} \mathrm{C}\right)$ can be increased by copolymerization of NIPAAm with hydrophilic or ionized monomers [32, 33]. It was demonstrated that copolymerization of NIPAAm with amphiphilic weak acid monomers allows tuning the LCST of polyNIPAAm above body temperature [13]; this leads, in the case of nanohydrogels, to maintaining adequate swelling/deswelling properties [34,35].

In a previous study, our group has reported the synthesis of core cross-linked (CCS) temperature sensitive star polymers with a random number of poly $(N$-isopropylacrylamide)- $b$-poly(hexyl acrylate) (PNIPAAm- $b$-PHA) or PNIPAAm arms using the RAFT polymerization technique. Furthermore, the release behavior of different drugs from those star polymers was also investigated observing that a star polymer with PNIPAAm- $b$-PHA arms is more effective in entrapping drugs than a star polymer formed by pure PNIPAAm arms since the PHA block forms a hydrophobic intermediate shell over the core where hydrophobic drugs can be entrapped [12]. Other examples of PNIPAAm-based star polymers have been developed for drug delivery applications [21, 36-42]. However, most of them have been designed so as to be able to entrap and release the drug due to the ability of PNIPAAm star polymers to self-aggregate [21, 3641], which may have the drawback of early aggregate disruption due to the dilution factor in the bloodstream, resulting in premature drug release. CCS star polymers represent intermediate architecture between branched polymer chains and polymer nanoparticles [43]. They are larger than conventional star polymers, having a single molecule or atom as a core, but smaller than nano/microgels. They have the advantage of presenting a relatively large core (cargo compartment) depending on the synthetic conditions and they are surrounded by a large number of polymer arms that stabilize them, making them dispersible in a suitable solvent for the arms and preventing self-aggregation.

In the present study, the RAFT technique was employed to synthesize poly(NIPAAm-co-amphiphilic weak acid) polymers to tailor the LCST in the range of 40 to $46^{\circ} \mathrm{C}$ at pH of 7.4. These polymeric chains were further activated to form block copolymers with HA. The block copolymers were used to prepare dual sensitive, temperature and $\mathrm{pH}$, star polymers, cross-linked with ethyleneglycol dimethacrylate (EGDMA). These CCS star polymers were tested to load 5-fluorouracil (5-FU), an anticancer drug, and to study their drug delivery behavior under different in vitro conditions.

\section{Experimental Section}

2.1. Materials. The acid monomer, 4-methacryloyloxybenzoic acid (4MBA), the RAFT agent, 2-hydroxyethyl 2phenylacetate dithiobenzoate (DFH), and the free-radical initiator, 4,4' -azobis(4-cyanopentanol) (ACP), were prepared as described in the literature [13]. $N$-Isopropylacrylamide (NIPAAm, 97\%, Aldrich) was purified by recrystallization from n-hexane. 4,4'-Azobis(4-cyanopentanoic acid) (ACPA, $98 \%$, Fluka) was recrystallized from methanol. $n$-Hexyl acrylate (HA, Aldrich) and ethyleneglycol dimethacrylate (EGDMA, Aldrich) were purified by passing the reagents through an inhibitor remover column for benzoquinones (Aldrich). p-Dioxane (ACS grade, Fermont), diethyl ether (ACS grade, Fermont), tetrahydrofuran (THF, HPLC grade, Aldrich), and 5-fluorouracil (5-FU, Sigma) were used without further purification.

2.2. Synthesis of Linear Poly(NIPAAm) Arms (Macro-CTAs of PolyNIPAAm) and Statistical Copolymers of NIPAAm with $4 M B A$. Linear poly(NIPAAm), used to form the arms of star polymers, was synthesized with prescribed molecular weights via RAFT polymerization (Figure 1(a)). Poly(NIPAAm) arms were prepared using molar ratios of monomer:CTA: initiator of $180: 1.0: 0.2$, of $132: 1.0: 0.2$, and of $88: 1.0: 0.2$. Statistical copolymers were synthesized with various molar percentages of the acid comonomer in order to adjust the LCST above $37^{\circ} \mathrm{C}$. Poly(NIPAAm-co$4 \mathrm{MBA}$ ), aiming at $9 \%$ of $4 \mathrm{MBA}$, was synthesized using the same molar ratios that were used in the synthesis of linear poly(NIPAAm) considering the total amount of monomers NIPAAm + 4MBA in the molar ratio.

The general procedure was performed as follows: $0.049 \mathrm{~g}$ $(0.147 \mathrm{mmol})$ of DFH was stirred until it was completely dissolved in $3.0 \mathrm{~mL}$ of $p$-dioxane and poured into an ampoule containing a magnetic stir bar. $2.85 \mathrm{~g}(25.18 \mathrm{mmol})$ of NIPAAm, $0.2867 \mathrm{~g}(1.30 \mathrm{mmol})$ of $4 \mathrm{MBA}, 0.0074 \mathrm{~g}$ 
$(0.0295 \mathrm{mmol})$ of ACP, and $3.0 \mathrm{~mL}$ of $p$-dioxane were added to that ampoule under continuous stirring. The ampoule was degassed by three freeze-thaw cycles alternating between vacuum and argon gas. The reaction mixture was heated to $70^{\circ} \mathrm{C}$ under argon atmosphere, and the polymerization was performed over $16 \mathrm{~h}$. The reaction mixture was cooled down to $25^{\circ} \mathrm{C}$ and the polymerization product was precipitated in diethyl ether, then redissolved in acetone, and finally precipitated in cold diethyl ether. The purification process was repeated three times; then, the solvent was removed under vacuum and the product was allowed to dry overnight in a vacuum oven at $25^{\circ} \mathrm{C}$.

\subsection{Preparation of Linear Blocks of Poly(NIPAAm)-b-} poly(hexyl acrylate, HA) and Poly(NIPAAm-co-4MBA)-bpoly(HA) Arms (Macro-CTAs of Block Copolymers). The same procedure described above for the preparation of linear poly(NIPAAm) macro-CTAs was followed (Figure 1(b)). Briefly, $1 \mathrm{~g}(0.3435 \mathrm{mmol})$ of PNIPAAm macro-CTA (used instead of DFH) was stirred until it was fully dissolved in $2.5 \mathrm{~mL}$ of $p$-dioxane and the resulting mixture was added to an ampoule containing a magnetic stir bar; $0.1799 \mathrm{~g}$ $(1.15 \mathrm{mmol})$ of HA monomer, $0.00173(0.00687 \mathrm{mmol})$ of $\mathrm{ACP}$, and $2.5 \mathrm{~mL}$ of $p$-dioxane were added to the ampoule under continuous stirring. The ampoule was degassed by three freeze-thaw cycles alternating between vacuum and argon gas. The reaction mixture was allowed to warm up to $70^{\circ} \mathrm{C}$ under argon atmosphere, and the polymerization was performed with stirring for $16 \mathrm{~h}$. The reaction mixture was cooled down to $25^{\circ} \mathrm{C}$ and the polymerization product was precipitated in diethyl ether, dissolved in acetone, and precipitated again in cold diethyl ether. The purification process was repeated three consecutive times. The solvent was removed under vacuum and the product was allowed to dry overnight in a vacuum oven at $25^{\circ} \mathrm{C}$. The same procedure was followed for the preparation of block copolymers starting with macro-CTAs of poly(NIPAAm-co-4MBA). The calculations were always done considering the same macroCTA to initiator molar ratio and the same volume of p-dioxane as the solvent of choice.

\subsection{Preparation of Star Polymers with a Cross-Linked Core.} The synthesis of star polymers using the "arm-first" RAFT method with cross-linking was adapted from procedures reported in the literature $[12,13,44,45]$ (Figure 1(c)). Different molar ratios of cross-linker to arms were used to prepare stars polymers with PNIPAAm- $b$-PHA arms. An example is described as follows: $0.6 \mathrm{~g}(0.0187 \mathrm{mmol})$ of PNIPAAm- $b$ PHA macro-CTA was stirred until it was fully dissolved in $2.4 \mathrm{~mL}$ of $p$-dioxane and poured into an ampoule containing a magnetic stir bar; $0.037 \mathrm{~g}(0.187 \mathrm{mmol})$ of EGDMA, $0.00094 \mathrm{~g}(0.00374 \mathrm{mmol})$ of ACP, and $1.5 \mathrm{~mL}$ of $p$-dioxane were added to the ampoule under continuous stirring. The ampoule was degassed by three freeze-thaw cycles alternating between vacuum and argon gas. The reaction mixture was allowed to warm up to $70^{\circ} \mathrm{C}$ under argon atmosphere, and the polymerization was performed under stirring for $24 \mathrm{~h}$. The reaction mixture was cooled down to $25^{\circ} \mathrm{C}$ and the polymerization product was precipitated in diethyl ether, redissolved in acetone, and precipitated again in cold diethyl ether. The purification process was repeated three times. The solvent was removed under vacuum and the product was allowed to dry overnight in a vacuum oven at $25^{\circ} \mathrm{C}$.

For the synthesis of star polymers with poly(NIPAAm-co4MBA)- $b$-PHA arms, a molar ratio of EGDMA : macro-CTA $=10: 1$ was used with macro-CTA poly(NIPAAm-co$\left.4 \mathrm{MBA}_{5 \%}\right)$ - $b$-PHA $\left(M_{n}=28,570 \mathrm{~g} \mathrm{~mol}^{-1}\right)$; and EGDMA: macro-CTA ratio $=20: 1$ was used with poly(NIPAAm-co$\left.4 \mathrm{MBA}_{9 \%}\right)$ - $b$-PHA $\left(M_{n}=21,730 \mathrm{~g} \mathrm{~mol}^{-1}\right)$. ACPA was used as the initiator and a 5:1 molar ratio of macro-CTA: initiator was used in all the cases. The polymerization procedure is the same as the one described above.

2.5. Characterization and Measurements. The polymerization yields were determined gravimetrically. The molecular weights and dispersity $\left(\boxplus=M_{w} / M_{n}\right)$ were determined by gel permeation chromatography (GPC). The GPC system consists of a Varian 9002 HPLC pump equipped with a refractive index detector (Varian RI-4), a triangle light scattering detector (Mini Dawn, $\lambda=690 \mathrm{~nm}$, Wyatt), and Phenomenex separation columns: Phenogel $10 \mu \mathrm{m} 500 \AA(00 \mathrm{H}-$ 0643-K0); Phenogel $10 \mu \mathrm{m} 104 \AA$ (00H-0645-K0); Phenogel $10 \mu \mathrm{m} 105 \AA(00 \mathrm{H}-0646-\mathrm{K} 0)$ in series. The mobile phase used in the GPC was tetrahydrofuran (THF, HPLC grade) for NIPAAm polymers (homopolymers, block copolymers, and star polymers) and $\mathrm{THF} / \mathrm{CH}_{3} \mathrm{COOH}(50: 1) \mathrm{v} / \mathrm{v}$ for copolymers, block copolymers, and star polymers containing acid comonomer units, while the flow rate was $0.5 \mathrm{~mL} \mathrm{~min}^{-1}$ at $25^{\circ} \mathrm{C}$. Monodisperse polystyrene was used as the calibration standard to confirm the accuracy of the light scattering detector. $d n / d c=0.093 \mathrm{~mL} / \mathrm{g}$ [46], reported for polyNIPAAm in THF, was used for molecular weight determinations of all polymers without HA. For polymers containing HA, an average $d n / d c$ value between that of polyNIPAAm and that reported for polybutylacrylate in THF $(0.065 \mathrm{~mL} / \mathrm{g}$ [47]) was used, namely, $0.079 \mathrm{~mL} / \mathrm{g}$.

Dynamic light scattering (DLS) was used to determine the hydrodynamic diameters $\left(D_{h}\right)$. Measurements were carried out at $20^{\circ} \mathrm{C}$ using a Zeta-sizer "Nano-ZS" from Malvern Instruments (ZEN3500) equipped with a green laser operating at $\lambda=532 \mathrm{~nm}$. The angle of measurement was $173^{\circ}$ (backscattering) and the size analysis was performed by CONTIN. The reported hydrodynamic diameters were calculated using the Stokes-Einstein equation for spheres [48]. Reported $D_{h}$ values were the maxima in size distribution by volume from CONTIN analysis. The scattering intensity as a function of temperature was also used to determine the phase transition temperature of the prepared NIPAAm polymers at a given concentration, called, for the sake of simplicity, lower critical solution temperature (LCST). The size analysis was performed at different temperatures using $3 \mathrm{~min}$ of equilibrating time at each temperature in a heating cycle. The polymer concentration was $1 \mathrm{mg} \mathrm{mL}^{-1}$ and the value reported for the LCST was the temperature at which the scattering intensity increased sharply. The solutions were prepared, shaken for $12 \mathrm{~h}$, and stored overnight in the refrigerator at $4^{\circ} \mathrm{C}$. Before measurements, the solutions were filtered off using a 0.45 -micron syringe filter for eliminating dust. 


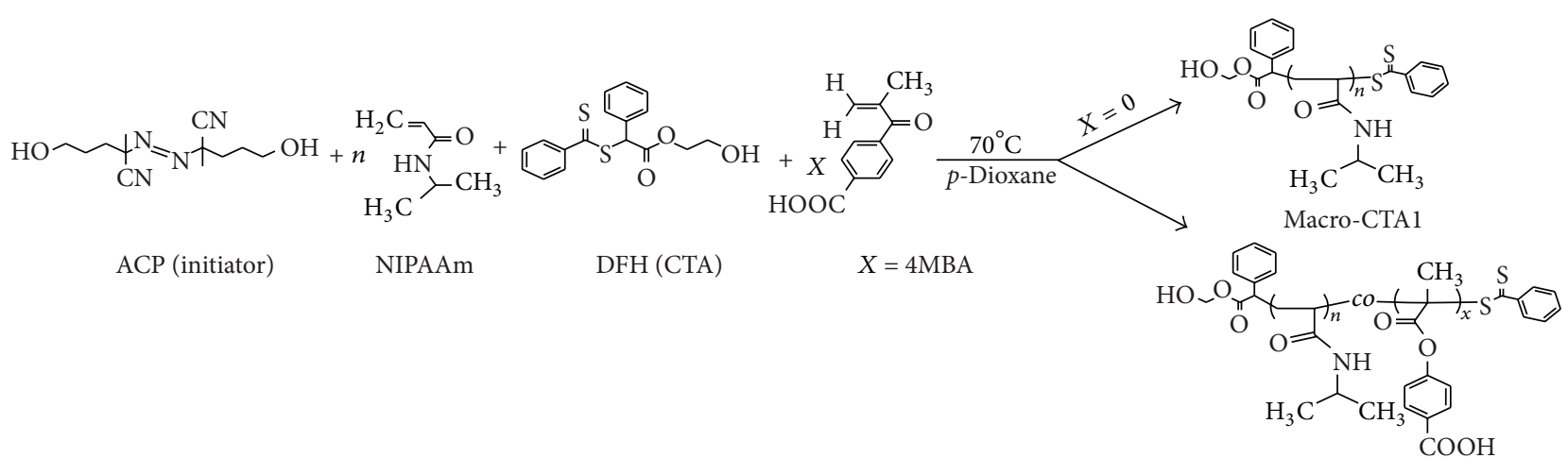

Macro-CTA2

(a)

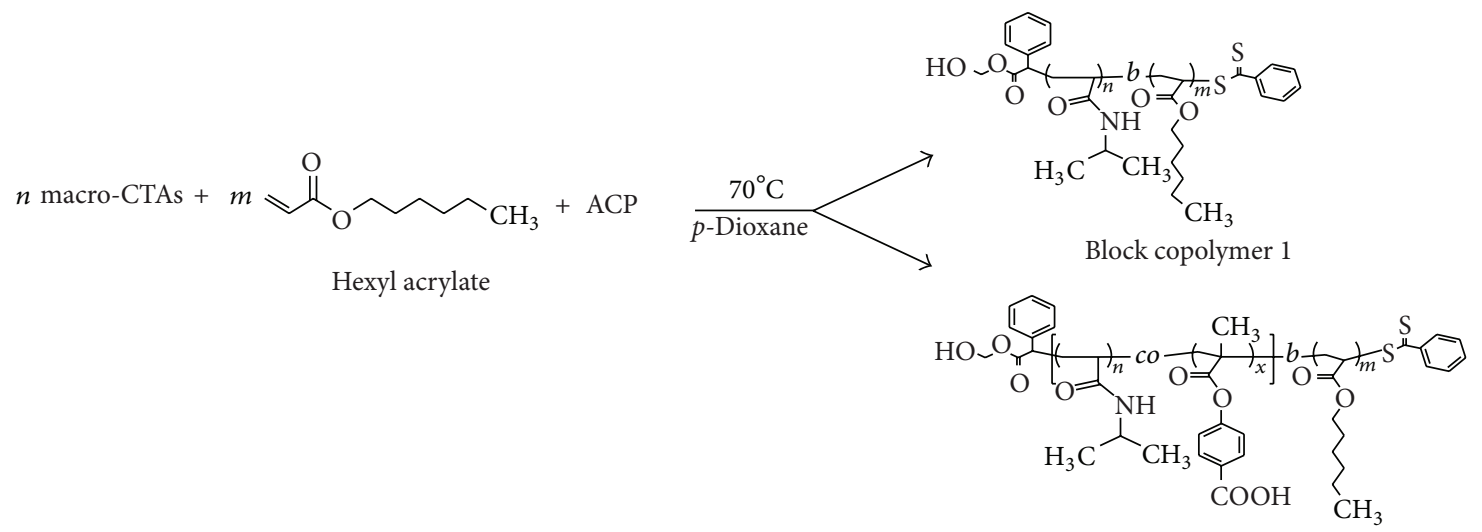

Block copolymer 2

(b)
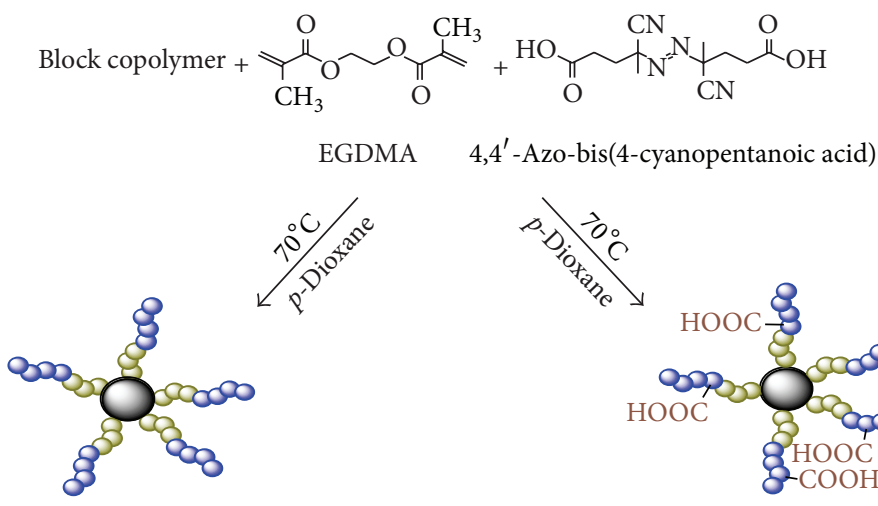

$\infty$ NIPAAm

O HA

EGDMA cross linker

(c)

FIGURE 1: Synthetic routes to obtain $\mathrm{pH}$ and temperature sensitive star polymers.

${ }^{1} \mathrm{H}-\mathrm{NMR}$ spectra were recorded on a Varian Mercury $200 \mathrm{MHz}$ nuclear magnetic resonance instrument with $\mathrm{CDCl}_{3}$ or $\mathrm{CD}_{3} \mathrm{OD}$ as the solvents and tetramethylsilane (TMS) as the internal reference. Atomic force microscopy
(AFM) imaging experiments were performed using an Agilent Technologies SPM 5100 microscope equipped with N9520A high resolution scanner. The samples were prepared by dissolving the star polymer in a small volume of THF 
TABLE 1: Preparation of linear macro-CTAs at $70^{\circ} \mathrm{C}$ in $p$-dioxane for $12 \mathrm{~h}$.

\begin{tabular}{|c|c|c|c|c|c|c|}
\hline Entries & Polymer & $\mathrm{M}: \mathrm{CTA}: \mathrm{I}^{\mathrm{a}}$ & $\begin{array}{c}M_{n} \text { (target) } \\
(\mathrm{g} / \mathrm{mol})\end{array}$ & $\begin{array}{c}M_{n}(\mathrm{GPC}) \\
(\mathrm{g} / \mathrm{mol})\end{array}$ & $\begin{array}{c}Ð \\
\left(M_{w} / M_{n}\right)\end{array}$ & Yield (wt\%) \\
\hline 1 & PolyNIPAAm & $180: 1: 0.2$ & $20,673^{b}$ & 26,100 & 1.008 & 75 \\
\hline 2 & PolyNIPAAm & $132: 1: 0.2$ & $15,249^{\mathrm{b}}$ & 14,400 & 1.022 & 70 \\
\hline 3 & PolyNIPAAm & $88: 1: 0.2$ & $10,277^{\mathrm{b}}$ & 10,800 & 1.030 & 73 \\
\hline 4 & PolyNIPAAm & $88: 1: 0.2$ & $10,277^{\mathrm{b}}$ & 8,200 & 1.040 & 70 \\
\hline 5 & Poly(NIPAAm-co-4MBA ${ }_{5 \%}$ ) & $180: 1: 0.2$ & $21,510^{\mathrm{c}}$ & 22,000 & 1.157 & 78 \\
\hline 6 & Poly(NIPAAm-co-4MBA ${ }_{9 \%}$ ) & $132: 1: 0.2$ & $16,354^{\mathrm{c}}$ & 15,200 & 1.149 & 70 \\
\hline
\end{tabular}

${ }^{\mathrm{a}} \mathrm{M}$ : monomer; CTA: chain transfer agent; I: initiator.

${ }^{\mathrm{b}} M_{n}$ (target) $=\left([M]_{0} /[\mathrm{CTA}]_{0}\right) M_{\mathrm{Mon}}+M_{\mathrm{CTA}}$.

${ }^{\mathrm{c}} M_{n}($ target $)=\left([\mathrm{NIPAAm}]_{0} /[\mathrm{CTA}]_{0}\right) M_{\mathrm{NIPAAm}}+\left([4 \mathrm{MBA}]_{0} /[\mathrm{CTA}]_{0}\right) M_{4 \mathrm{MBA}}+M_{\mathrm{CTA}}$.

and then dispersing it in deionized water. The volumes and amounts were adjusted to obtain a concentration of $0.1 \mathrm{mg} \mathrm{mL}^{-1}$ in water. Then, the polymer solutions were filtered through a $0.45 \mu \mathrm{m}$ syringe filter, followed by dropcasting on a freshly cleaved mica wafer, and dried in a controlled temperature room at $20^{\circ} \mathrm{C}$ for $24 \mathrm{~h}$. The AFM experiments were carried out using the intermittent contact mode with silicon cantilevers at ambient conditions. For each sample, three to four images were recorded from the same slide and the diameter of the assemblies was measured. The average value of the assemblies is reported as the average diameter of the star polymers.

2.6. Drug Loading and In Vitro Drug Release. 5-FU (8 mg) was dissolved in $1.5 \mathrm{~mL}$ of dimethylacetamide (DMAc), while the star polymer $(4 \mathrm{mg}$ ) was dissolved in $1.5 \mathrm{~mL}$ of DMAc in a separate vial. The drug solution was added dropwise to the star polymer solution with stirring at $20^{\circ} \mathrm{C}$. The resulting solution was poured into a dialysis bag (molecular weight cutoff: $12,000-14,000$ daltons) and it was subjected to dialysis against distilled water for $4 \mathrm{~h}$ to remove the nonencapsulated drug. The distilled water was replaced every $30 \mathrm{~min}$ for the first $2 \mathrm{~h}$. The dialyzed solution was then lyophilized. The freeze-dried samples of drug-loaded star polymers were dispersed in a phosphate buffer (PBS) at $\mathrm{pH}$ of 7.4, followed by stirring them vigorously for $2 \mathrm{~h}$ and then sonicating them for $15 \mathrm{~min}$. The loading amount of 5-FU in the star polymers was determined by measuring the UV absorbance at $267 \mathrm{~nm}$ using a Beckman Coulter spectrometer DU520. The drug loading (DL\%) and entrapment efficiency (EE\%) of the star polymer were calculated as follows:

$$
\begin{aligned}
& \mathrm{DL} \%=\left(\frac{\text { MDstar }}{\text { mass of stars }+ \text { MDstar }}\right) \times 100, \\
& \mathrm{EE} \%=\left(\frac{\text { initial MD }- \text { MDsupernatant }}{\text { initial MD }}\right) \times 100,
\end{aligned}
$$

where MD is the mass of drug (5-FU) and MDstar is the mass of drug in the star polymer. For the release experiments, the drug-loaded star polymers were placed into dialysis bags $(10 \mathrm{~mL})$ and dialyzed against $250 \mathrm{~mL}$ (sink conditions) of PBS at $\mathrm{pH}$ of 7.4 or at $\mathrm{pH}$ of 6 , in a shaking bath (VWR International, model number 1217) with mild shaking motion $(20 \mathrm{rpm})$ at 37 and $42^{\circ} \mathrm{C}$, respectively. At predetermined time intervals, a $1 \mathrm{~mL}$ aliquot of the released medium was taken out and assayed for 5-FU content, and $1 \mathrm{~mL}$ of fresh buffer solution was replaced into the release media every predetermined time interval. The concentration of 5-FU released from the drug delivery system was monitored by measuring the UV absorbance at $267 \mathrm{~nm}$ using a Beckman Coulter spectrometer DU520. The cumulative drug release was calculated from the relationship based on the standard calibration curve. All the analyses were performed in triplicate and the results were reported with an average of three runs.

\section{Results and Discussion}

3.1. Synthesis of Macro-CTAs. The chemical, molecular, and size analysis of polyNIPAAm and the statistical copolymer poly(NIPAAm-co-4MBA) as macro-CTAs were studied using FT-IR, ${ }^{1} \mathrm{H}-\mathrm{NMR}, \mathrm{GPC}$, and DLS as analytical tools. The number average molecular weights $\left(M_{n}\right)$ for polyNIPAAmbased macro-CTAs are defined by the NIPAAm to CTA molar ratio, as expected for a controlled radical polymerization method like RAFT. The dispersity values $(\boxplus)$ obtained for polyNIPAAm were very low (Table 1, entries 1 to 4 ) demonstrating well behaving RAFT polymerization.

A similar behavior can be observed in the case of the poly(NIPAAm-co-4MBA) statistical copolymers, showing $Đ$ values below 1.16 (entries 5-6 in Table 1). These values suggest that the polymerization proceeded in all cases with a high level of control. The polymerization yields ranged from 70 to $78 \%$.

3.2. Synthesis of Block Copolymers. The main interest of introducing a second hydrophobic block constituted of $n$-hexyl acrylate (HA) units into polyNIPAAm or poly(NIPAAm-co4MBA) linear polymers was to synthesize star polymers with a hydrophobic shell over the cross-linked core, which are able to retain drugs for transport in physiological conditions. The hydrophobic PHA block may also lead to star aggregate formation depending on the relative block size and number of arms of the star. Previously, the monomer HA had been successfully grown under RAFT polymerization conditions to form block copolymers with polyNIPAAm to generate polyNIPAAm- $b$-polyHA [12] and poly(NIPAAm-co-4MBA)$b$-polyHA [13]. The molecular weights of the obtained products in this work are shown in Table 2. 
TABLE 2: Preparation of linear block copolymer arms.

\begin{tabular}{|c|c|c|c|c|c|c|}
\hline Entries & Polymer & $\mathrm{M}: \mathrm{CTA}: \mathrm{I}^{\mathrm{a}}$ & $\begin{array}{c}M_{n}{\text { (target })^{\mathrm{i}}}^{(\mathrm{g} / \mathrm{mol})}\end{array}$ & $\begin{array}{c}M_{n}(\mathrm{GPC}) \\
(\mathrm{g} / \mathrm{mol})\end{array}$ & $\begin{array}{c}Ð \\
\left(M_{w} / M_{n}\right) \\
\end{array}$ & Yield (wt\%) \\
\hline 1 & PolyNIPAAm- $b$-polyHA & $22: 1: 0.2^{\mathrm{b}}$ & 11,645 & 12,780 & 1.065 & 70 \\
\hline 2 & PolyNIPAAm- $b$-polyHA & $32: 1: 0.2^{\mathrm{c}}$ & 15,820 & 17,890 & 1.175 & 70 \\
\hline 3 & PolyNIPAAm- $b$-polyHA & $50: 1: 0.2^{\mathrm{d}}$ & 19,930 & 20,200 & 1.137 & 72 \\
\hline 4 & PolyNIPAAm- $b$-polyHA & $32: 1: 0.2^{\mathrm{e}}$ & 31,111 & 32,070 & 1.177 & 75 \\
\hline 5 & Poly(NIPAAm-co- $4 \mathrm{MBA}_{9 \%}$ )- $b$-polyHA & $32: 1: 0.2^{\mathrm{f}}$ & 21,160 & 21,730 & 1.030 & 71 \\
\hline 6 & Poly(NIPAAm-co- $4 \mathrm{MBA}_{9 \%}$ )- $b$-polyHA & $64: 1: 0.2^{\mathrm{g}}$ & 25,160 & 25,340 & 1.011 & 65 \\
\hline 7 & Poly(NIPAAm-co-4MBA $5 \%$ )- $b$-polyHA & $32: 1: 0.2^{\mathrm{h}}$ & 27,200 & 28,570 & 1.038 & 60 \\
\hline
\end{tabular}

${ }^{\mathrm{a}}$ Reactions in $p$-dioxane at $70^{\circ} \mathrm{C}$ for $16 \mathrm{~h}, \mathrm{M}=\mathrm{HA} ;{ }^{\mathrm{b}}$ macro-CTA is PNIPAAm $\left(M_{n}=8,208 \mathrm{~g} / \mathrm{mol}\right) ;{ }^{\mathrm{c}}$ macro-CTA is PNIPAAm $\left(M_{n}=10,820 \mathrm{~g} / \mathrm{mol}\right)$; ${ }^{\mathrm{d}}$ macro-CTA is PNIPAAm $\left(M_{n}=14,430 \mathrm{~g} / \mathrm{mol}\right) ;{ }^{\mathrm{e}}$ macro-CTA is PNIPAAm $\left(M_{n}=26,110 \mathrm{~g} / \mathrm{mol}\right) ;{ }^{\mathrm{f}}$ macro-CTA is $\mathrm{P}(\mathrm{NIPAAm}-c o-4 \mathrm{MBA} \%)\left(M_{n}=\right.$ $15,160 \mathrm{~g} / \mathrm{mol}) ;{ }^{\mathrm{g}}$ macro-CTA is P(NIPAAm-co- $\left.4 \mathrm{MBA}_{9 \%}\right)\left(M_{n}=15,160 \mathrm{~g} / \mathrm{mol}\right) ;{ }^{\mathrm{h}}$ macro-CTA is P(NIPAAm-co- $\left.4 \mathrm{MBA}_{5 \%}\right)\left(M_{n}=22,000 \mathrm{~g} / \mathrm{mol}\right) ;{ }^{\mathrm{i}} M_{n}(\operatorname{target})=$ $\left([M]_{0} /[\text { macro-CTA }]_{0}\right) M_{\text {Mon }}+M_{\text {macro-CTA }}$.

TABLE 3: Reactions for preparation of star polymers with a random number of arms and a cross-linked poly(EGDMA) core.

\begin{tabular}{|c|c|c|c|c|c|}
\hline Entries & $\begin{array}{c}\text { Star polymer } \\
{[\text { cross-linker : macro-CTA : I }]^{\mathrm{a}}}\end{array}$ & Crosslinker : macro-CTA : $\mathrm{I}^{\mathrm{a}}$ & $\begin{array}{c}M_{n}(\mathrm{GPC}) \\
(\mathrm{g} / \mathrm{mol})\end{array}$ & $\begin{array}{c}Ð \\
\left(M_{w} / M_{n}\right)\end{array}$ & Yield (wt\%) \\
\hline 1 & [PolyNIPAAm- $b$-polyHA] ${ }^{\mathrm{b}}$-EGDMA & $20: 1: 0.2$ & 41,740 & 1.333 & 70 \\
\hline 2 & [PolyNIPAAm- $b$-polyHA $]^{c}$-EGDMA & $10: 1: 0.2$ & 136,500 & 1.200 & 77 \\
\hline 3 & $[($ Poly(NIPAAm-co-4MBA $9 \%)-b$-polyHA $)]^{\mathrm{d}}$-EGDMA & $20: 1: 0.2$ & 76,600 & 1.175 & 65 \\
\hline 4 & {$\left[\left(\mathrm{Poly}\left(\mathrm{NIPAAm}-c o-4 \mathrm{MBA}_{5 \%}\right)-b \text {-polyHA }\right)\right]^{\mathrm{e}}$-EGDMA } & $10: 1: 0.2$ & 100,700 & 1.290 & 70 \\
\hline
\end{tabular}

${ }^{\mathrm{a} C r o s s-l i n k e r: ~ E G D M A ; ~ m a c r o-C T A: ~ b l o c k ~ c o p o l y m e r ~ a s ~ m a c r o ~ c h a i n ~ t r a n s f e r ~ a g e n t ; ~ I: ~ i n i t i a t o r . ~}{ }^{\mathrm{b}}$ Macro-CTA of $M_{n}=12,780 \mathrm{~g} / \mathrm{mol}^{\mathrm{c}}{ }^{\mathrm{M}} \mathrm{Macro-CTA}$ of $M_{n}=$ $32,070 \mathrm{~g} / \mathrm{mol}$. ${ }^{\mathrm{d}}$ Macro-CTA of $M_{n}=21,730 \mathrm{~g} / \mathrm{mol}$. ${ }^{\mathrm{e}}$ Macro-CTA of $M_{n}=28,570 \mathrm{~g} / \mathrm{mol}$.

Results in Table 2 showed that polyNIPAAm was reacted with different molar ratios of $\mathrm{HA}$ to form the second block. In each case, a comparison between observed and target molecular weights showed that they were similar, demonstrating good RAFT copolymerization control resulting in $Đ$ values below 1.2 (entries 1 to 4 ). Indeed, when using the same molar ratio of HA to macro-CTA but polyNIPAAm macro-CTAs with different $M_{n}$ values, $Đ$ values were not affected (entries 2 and 4). The same results regarding the high level of control can be observed for the formation of poly(NIPAAm-co4MBA)- $b$-(polyHA) using as macro-CTAs statistical copolymers which have different molar ratios of $4 \mathrm{MBA}$ and even different lengths of the macro-CTA chain. In all the cases, good match was observed between the calculated and the observed molecular weights with low $Đ$ values (entries 5 to 7). The obtained yields were in a range of 60 to $75 \%$.

3.3. Synthesis of Star Polymers. The star polymers were prepared from the block copolymers presented in Section 3.2. The block copolymers represent the arms of the star. The molar ratios of cross-linker to arms EGDMA : polyNIPAAm$b$-polyHA or EGDMA : poly(NIPAAm-co-4MBA)- $b$-polyHA for the preparation of the corresponding star polymers are shown in Table 3. The molecular weights that were obtained from GPC for the products prepared at 10:1 and 20:1 ratios are, in most of the cases, three to four times the molecular weight of the arms. These molecular weights are lower than the expected values according to literature reports for this type of star polymer, where more arms per star were expected
$[17,43]$, nevertheless enough to suggest that star polymers are formed. Figure 2 shows a comparison between GPC traces for a linear copolymer, a block copolymer prepared from it (arm), and a star polymer as a result of the final reaction of the block copolymer with the cross-linker. Results reveal narrow size distributions for the linear and block copolymers and a wider distribution for the star polymer, while the retention time decreases with increasing size, as expected.

The star polymers were characterized by spectroscopy analysis. FT-IR and ${ }^{1} \mathrm{H}-\mathrm{NMR}$, spectra of a 10:1 star product, are shown in Figure 3. The spectroscopic analysis confirmed the incorporation of both HA and EGDMA units into the star polymer; however, the EGDMA units were difficult to be identified separately from HA or 4MBA units (Figures $3(\mathrm{a})$ and $3(\mathrm{~b}))$. The FT-IR spectrum of the star polymer with poly(NIPAAm-co-4MBA $5 \%$ )- $b$-polyHA linear arms showed strong carbonyl stretching vibration of the polyNIPAAm amide groups at $1641 \mathrm{~cm}^{-1}$ and a strong carbonyl stretching band at $1731 \mathrm{~cm}^{-1}$ corresponding to the ester groups of both HA and EGDMA units. Furthermore, stretching vibration of aromatic C-H at $3074 \mathrm{~cm}^{-1}$ and at $3295 \mathrm{~cm}^{-1}$ (O-H) demonstrates the presence of the 4MBA units (Figure 3(a)). In the case of the ${ }^{1} \mathrm{H}$-NMR spectrum, the characteristic signal at $4 \mathrm{ppm}$ corresponds to the methine proton on the isopropyl groups present in polyNIPAAm (signal d) and to the methylene protons attached to the HA and EGDMA ester groups (signals 1 and $\mathrm{q}, \mathrm{q}^{\prime}$ ), respectively, whereas in the case of the 4MBA units in the linear arms, the chemical shifts of aromatic protons (signals $h$ and i) are observed at 7.2 and 
TABLE 4: Hydrodynamic diameters and LCST values of star polymers, in PBS at pH 6 and in PBS at pH 7.4.

\begin{tabular}{|c|c|c|c|c|c|c|c|}
\hline \multirow{2}{*}{ Entries } & \multirow{2}{*}{ Star polymer } & \multicolumn{2}{|c|}{ PBS, pH 6} & \multirow{2}{*}{$\begin{array}{c}\text { LCST, pH } \\
6 \\
\text { Temp. }\left({ }^{\circ} \mathrm{C}\right)\end{array}$} & \multicolumn{2}{|c|}{ PBS, pH 7.4} & \multirow{2}{*}{$\begin{array}{c}\text { LCST, pH } \\
7.4 \\
\text { Temp. }\left({ }^{\circ} \mathrm{C}\right)\end{array}$} \\
\hline & & $D_{h}(\mathrm{~nm})$ & $p d i$ & & $D_{h}(\mathrm{~nm})$ & $p d i$ & \\
\hline 1 & 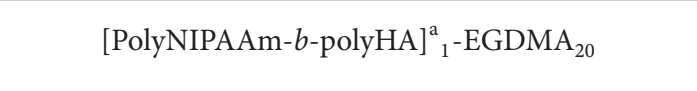 & - & - & - & $65.38 \pm 4.4$ & $\begin{array}{c}0.397 \pm \\
7 e^{-3}\end{array}$ & 32 \\
\hline 2 & {$[\text { PolyNIPAAm- } b \text {-polyHA }]_{1}^{\mathrm{b}}$-EGDMA $_{10}$} & - & - & 30 & $108.8 \pm 3.6$ & $\begin{array}{l}0.256 \pm \\
0.02\end{array}$ & 30 \\
\hline 3 & 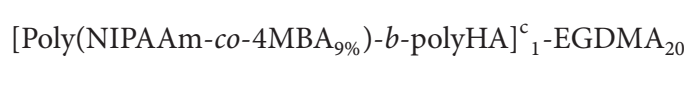 & $\begin{array}{c}62.74 \pm \\
0.62\end{array}$ & $\begin{array}{c}0.257 \pm \\
1 e^{-3}\end{array}$ & 36 & $94.68 \pm 1.5$ & $\begin{array}{c}0.187 \pm \\
8 e^{-3}\end{array}$ & 46 \\
\hline 4 & {$[\text { Poly(NIPAAm-co-4MBA } 5 \% \text { )- } b \text {-polyHA }]_{1}^{\mathrm{d}}-\mathrm{EGDMA}_{10}$} & $112.4 \pm 4.8$ & $\begin{array}{c}0.326 \pm \\
0.03\end{array}$ & 36 & $\begin{array}{c}171.03 \pm \\
0.6\end{array}$ & $\begin{array}{c}0.302 \pm \\
0.02\end{array}$ & 40 \\
\hline
\end{tabular}

${ }^{\mathrm{a}}$ Macro-CTA of $M_{n}=12,780 \mathrm{~g} / \mathrm{mol} .{ }^{\mathrm{b}}$ Macro-CTA of $M_{n}=32,070 \mathrm{~g} / \mathrm{mol} .{ }^{\mathrm{c}}$ Macro-CTA of $M_{n}=21,730 \mathrm{~g} / \mathrm{mol}$. ${ }^{\mathrm{d}} \mathrm{Macro}-\mathrm{CTA}$ of $M_{n}=28,570 \mathrm{~g} / \mathrm{mol}$.

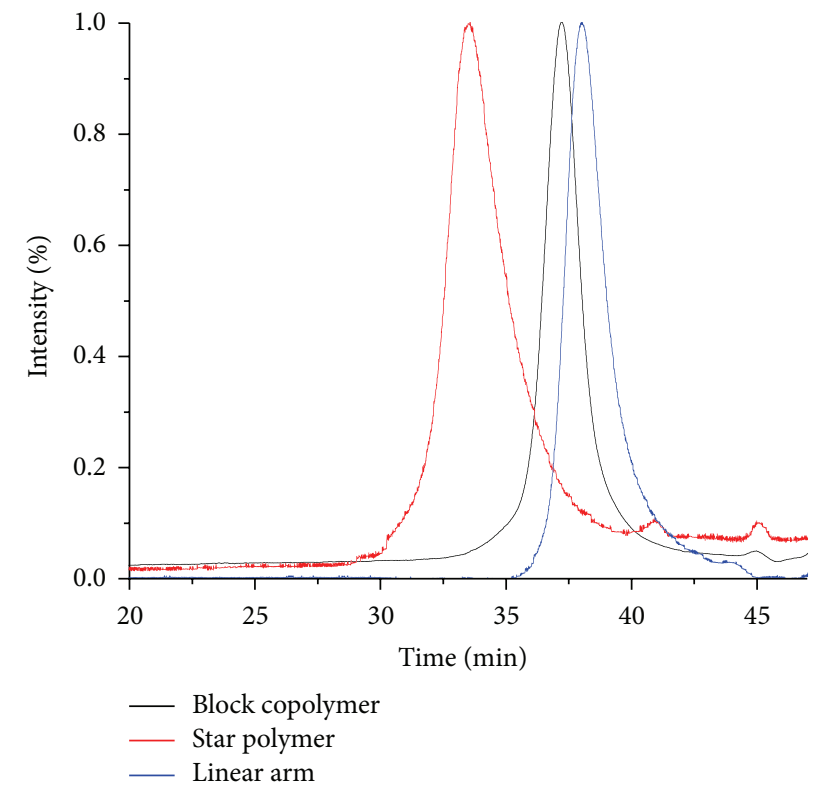

FIGURE 2: GPC traces of poly(NIPAAm-co- $4 \mathrm{MBA}_{5 \%}$ ) (blue), poly(NIPAAm-co-4MBA ${ }_{5 \%}$ )- $b$-polyHA (black), and [poly(NIPAAmco- $\left.4 \mathrm{MBA}_{5 \%}\right)$ - $b$-polyHA $]_{1}-\mathrm{EGDMA}_{10}(\mathrm{red})$.

8 ppm, respectively; other signals are superimposed and were assigned as shown in that spectrum (Figure 3(b)).

The DLS technique was also used to characterize the materials. Figure 4(a) shows the hydrodynamic diameters $\left(D_{h}\right)$ of poly(NIPAAm-co-4MBA $\left.{ }_{5 \%}\right)$, poly(NIPAAmco-4 $\left.\mathrm{MBA}_{5 \%}\right)$ - $b$-polyHA, linear arms, and star polymer [poly(NIPAAm-co-4MBA $5 \%$ )- $b$-polyHA $]_{1}-$ EGDMA $_{10}$, all at $20^{\circ} \mathrm{C}$. As can be seen, the size of the materials increases in each synthetic step. Furthermore, the size increases from polymer arm $(\sim 10 \mathrm{~nm})$ to star polymer $(\sim 100 \mathrm{~nm})$ suggesting that the star polymer is not a simple star polymer with a congested core.

The core cross-linked star architecture may contain a loose core as described in [12]. Figure 4(b) shows the light scattering intensity at different temperatures for the materials at $\mathrm{pH}$ of 7.4. At a given temperature, an increase in the intensity is observed due to aggregation of the particles. We consider this point as the LCST of the materials. As can be observed, the LCST is the same for the copolymer and the block copolymer, whereas in the case of the star polymer it is shifted to lower temperatures. The LCST is originated from the poly(NIPAAm-co-4MBA) copolymer, first block of the star arms, and modified slightly by cross-linking with EGDMA.

To further investigate the obtained star polymer structures, $D_{h}$ was determined in buffer solutions; results are shown in Table 4 . The observed hydrodynamic diameter depends on the size of the arms and on the arms-to-crosslinker ratio. The larger the arms, the longer the star diameter, in agreement with the molecular weight of the stars; but also the smaller the cross-linker-to-arms ratio, the longer the star diameter. Lower cross-linker content in the star synthesis may result in a less congested core which may lead to star/star coupling reactions during polymerization, while higher cross-linker content in the synthesis may result in a more congested core hindering star-to-star coupling during the synthesis. In the case of the star polymers containing acid units, that is, the star polymer prepared using poly(NIPAAmco- $\left.4 \mathrm{MBA}_{5 \%}\right)$ - $b$-polyHA $\left(M_{n}=28,570 \mathrm{~g} / \mathrm{mol}\right)$ arms, the diameter $\left(D_{h}\right)$ depends also on the ionization of those acid units. In PBS, at pH 7.4, the tendency of contraction of hydrophobic polyHA units is counterbalanced by the expansion of arms due to ionization of $4 \mathrm{MBA}$ units. It was observed that $D_{h}$ value of star polymer in $\mathrm{PBS}$ at $20^{\circ} \mathrm{C}$ is smaller at $\mathrm{pH} 6$ than at $\mathrm{pH}$ 7.4. This might be directly related to the fact that at this $\mathrm{pH}$ value the $4 \mathrm{MBA}$ units are not completely ionized [49], contributing, together with polyHA units, to the increase in the hydrophobic balance resulting in shrinkage of the star polymer arms. The star polymer reported in entry 3 (Table 4) also shows a smaller diameter at $\mathrm{pH}$ 6. Therefore, the size of star polymers under certain solvent conditions, either organic or aqueous at certain $\mathrm{pH}$ value, results from balance of different contributions from the units present in the star polymer. The effect of $\mathrm{pH}$ on the LCST values of the prepared star polymers is also shown in Table 4 . In the case of the star polymer containing polyNIPAAm- $b$-polyHA arms in $\mathrm{PBS}$ at $\mathrm{pH} 7.4$, in the absence of 4MBA units (entries 1 and 2), the LCST values are in the range from 30 to $32^{\circ} \mathrm{C}$, which are typical values for the LCST of polyNIPAAm, whereas in the 


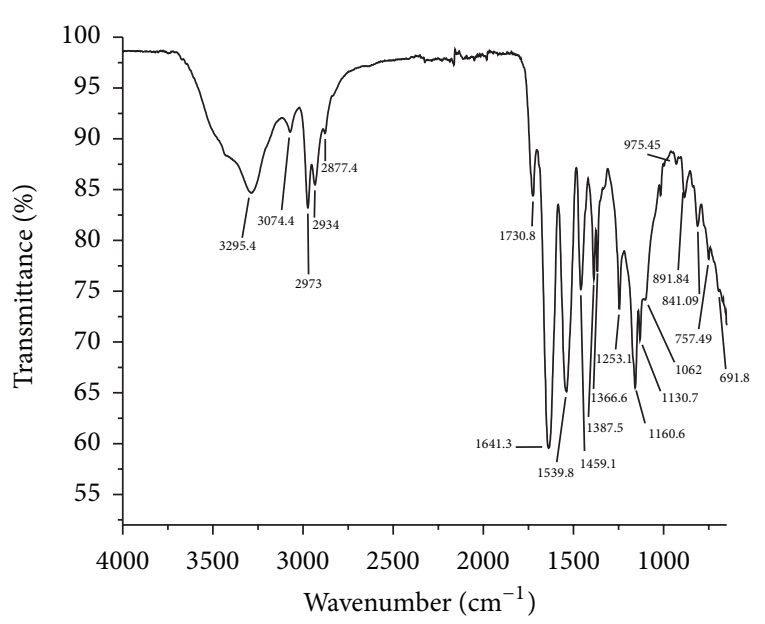

(a)

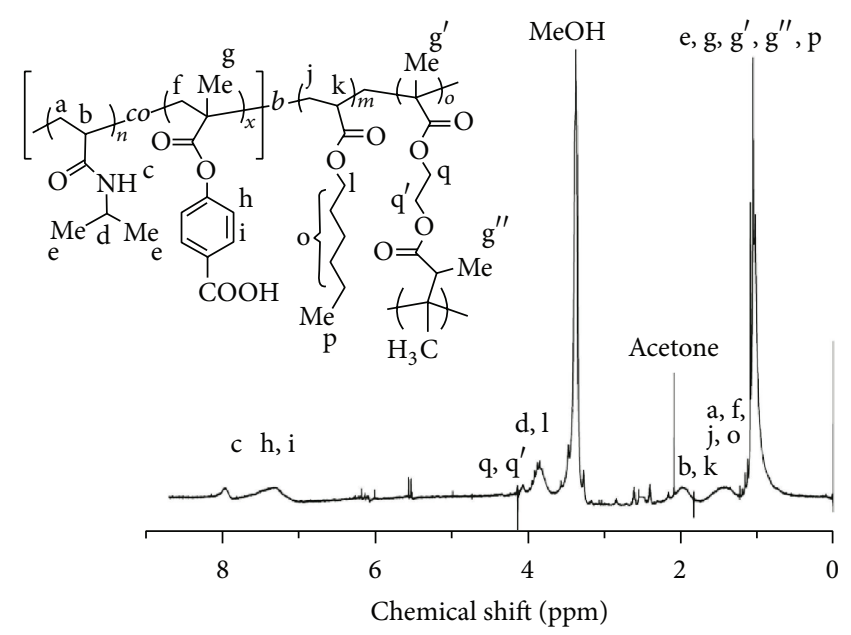

(b)

FIGURE 3: Spectra of star polymer [poly(NIPAAm-co-4MBA)- $b$-polyHA] ${ }_{1}$ EGDMA10: (a) FT-IR spectrum, (b) 1H-NMR spectrum (MeOD).

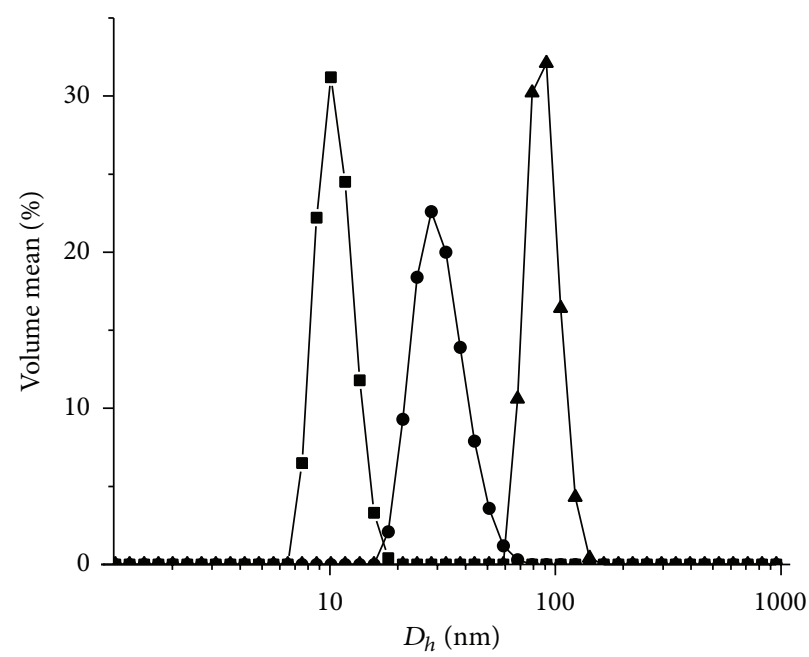

(a)

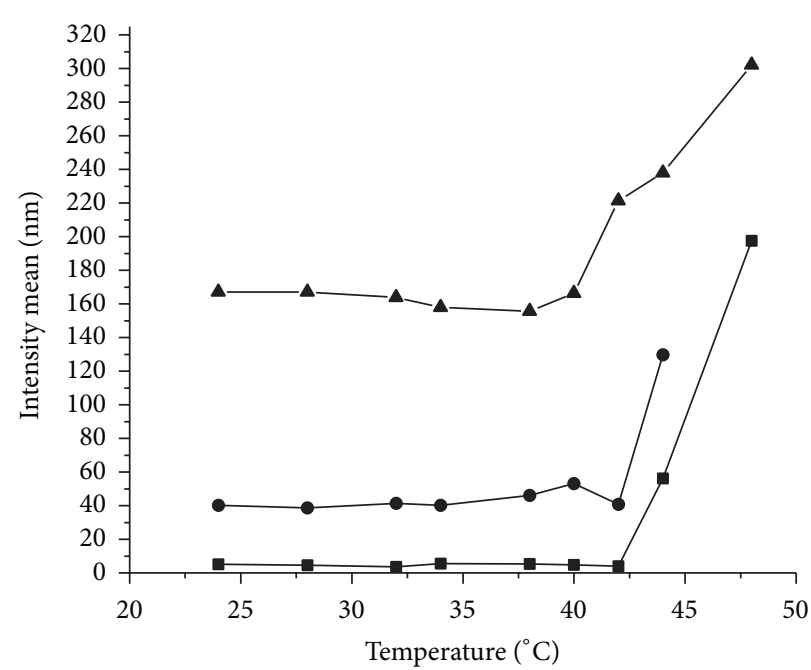

(b)

FIGURE 4: DLS results in PBS at $\mathrm{pH}$ 7.4: (a) hydrodynamic diameters at $20^{\circ} \mathrm{C}$, (b) light scattering intensity as a function of temperature. Symbols disclosure: poly(NIPAAm-co-4MBA $5 \%$ ), $M_{n}=22,000 \mathrm{~g} / \mathrm{mol}(\boldsymbol{\varpi})$; poly(NIPAAm-co- $\left.4 \mathrm{MBA}_{5 \%}\right)-b$-polyHA, $M_{n}=28,570 \mathrm{~g} / \mathrm{mol}(\bullet)$; and star polymer [poly(NIPAAm-co-4MBA $5 \%$ )- $b$-polyHA $]_{1}-\mathrm{EGDMA}_{10}, M_{n}=100,700 \mathrm{~g} / \mathrm{mol}(\mathbf{\Lambda})$.

case of star polymers containing [poly(NIPAAm-co-4MBA)$b$-polyHA] arms (entries 3 and 4), the observed LCST values were in the range from 40 to $46^{\circ} \mathrm{C}$ at $\mathrm{pH}$ of 7.4 , depending on the $4 \mathrm{MBA}$ content in the arms of the star. In Figure 5, the effect of $\mathrm{pH}$ on the LCST values of star polymers is shown.

The increase in the LCST at $\mathrm{pH} 7.4$ can be attributed to the presence of the acid comonomer 4MBA, taking into consideration the fact that its $\mathrm{p} K_{a}$ value is 5.3 [49]. As a result, at $\mathrm{pH} 7.4$, the majority of monomer units are ionized increasing the interaction with water and hence requiring a higher temperature for chain collapse to occur. The results of the LCST analysis in PBS at pH 6 are also shown in Table 4. In the case of star polymers containing [poly(NIPAAm-co-4MBA)- $b$-polyHA] arms (entries 3 and 4), the observed LCST values are $36^{\circ} \mathrm{C}$ which are lower than the LCST at pH 7.4 (see also Figure 5).

This is attributed to the decrease in the ionization degree of $4 \mathrm{MBA}$ at $\mathrm{pH} 6$ reducing the interaction with water. The results imply that this star polymer responds to changes in $\mathrm{pH}$ and temperature and that its LCST values at different $\mathrm{pH}$ values are optimized for drug delivery applications.

Further evidence of the star polymers morphology is obtained from the AFM analysis. In Figure 6, we can observe the morphology of [poly(NIPAAm-co-4MBA ${ }_{5 \%}$ )$b$-polyHA $]_{1}$-EGDMA 10 and [polyNIPAAm- $b$-polyHA $]_{1}$ $\mathrm{EGDMA}_{10}$ star polymers. The average value was 100.1 $\pm 12.4 \mathrm{~nm}$ of diameter with morphology like a well-defined oval for the star containing the acid units (4MBA) and 


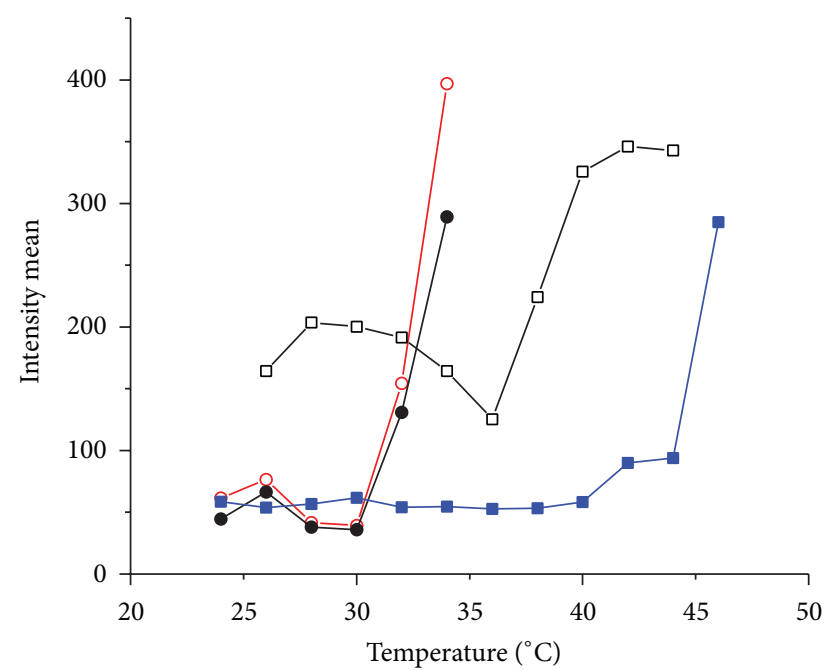

FIGURE 5: LCST of star polymers: star polymer [(PNIPAAm- $b$ polyHA) -EGDMA $_{10}$ ] in PBS at $\mathrm{pH} 7.4(\bullet)$ and in $\mathrm{PBS}$ at $\mathrm{pH} 6(\mathrm{O})$; star polymer [poly(NIPAAm-co-4MBA)-b-polyHA] ${ }_{1}-$ EGDMA $_{10}$ in PBS at pH 6 () and in PBS at pH 7.4 (匹).

$96.27 \pm 17.2 \mathrm{~nm}$ for the star without acid units. The sizes obtained by AFM are in good agreement with the DLS measurements $(112.4 \pm 4.8$, at $\mathrm{pH} \sim 6$ of aqueous dispersion, and $108.8 \pm 3.6 \mathrm{~nm}$, resp.); the slightly smaller sizes by AFM can be attributed to the drying process of the star polymers on the mica surface before measurement.

3.4. Drug Loading and Release Experiments. For the drug loading and release experiments, two star polymers were chosen with similar arm size and star architecture: the stars prepared with a 10:1 ratio of EGDMA : arms were selected since their arms are comparable in size: $M_{n}$ is $32070 \mathrm{~g} / \mathrm{mol}$ for polyNIPAAm- $b$-polyHA arms and $28570 \mathrm{~g} / \mathrm{mol}$ for poly(NIPAAm-co-4MBA ${ }_{5 \%}$ )- $b$-polyHA arms. As previously discussed, the LCST of the corresponding star polymers with polyNIPAAm- $b$-polyHA arms was $32^{\circ} \mathrm{C}$, whilst the LCST of the [(polyNIPAAm-co-4MBA $5 \%$ - $b$-polyHA $]_{1}-\mathrm{EGDMA}_{10}$ star was close to $40^{\circ} \mathrm{C}$ at $\mathrm{pH}$ of 7.4 and $36^{\circ} \mathrm{C}$ at $\mathrm{pH}$ of 6 , which are suitable for a dual sensitivity drug delivery system. The selected star polymers were loaded with 5 -FU by the dialysis method. The dialysis time plays an important role in the yield of loaded star polymers avoiding excess of nonbound drug. As the optimized dialysis time, a $4 \mathrm{~h}$ period was used to yield $30.5 \mathrm{w} / \mathrm{w} \%$ loading with $25 \%$ efficiency for the acid containing star polymer and $25.3 \mathrm{w} / \mathrm{w} \%$ loading and $16 \%$ efficiency for the star polymer without acid groups. Figure 7 shows a comparison of release profiles of 5-FU under different temperature and $\mathrm{pH}$ conditions. The free drug diffuses out of the dialysis bag in approximately $30 \mathrm{~min}$ (68\% cumulative release) at $37^{\circ} \mathrm{C}$ in medium at $\mathrm{pH}$ of 7.4 . In the case of the star that contains the acid monomer $4 \mathrm{MBA}$, at $\mathrm{pH} 7.4$ and $37^{\circ} \mathrm{C}(\mathrm{T}<\mathrm{LCST})$, a burst of $20 \%$ release at the beginning of the process $(20 \mathrm{~min})$ was observed, which may be related to the fact that 5-FU molecules are entrapped and distributed in the arms of the star and also at the interface between core and shell. However, the drug release is halted to $25 \%$ even after $26 \mathrm{~h}$, while at $42^{\circ} \mathrm{C}(T=\mathrm{LCST})$, the cumulative release increases to approximately $70 \%$ after $26 \mathrm{~h}$. At pH 6 and $37^{\circ} \mathrm{C}$ ( $T>$ LCST at these conditions), cumulative release of about $84 \%$ in $26 \mathrm{~h}$ was observed. On the other hand, the star without acid units (4MBA) shows cumulative release at $26 \mathrm{~h}$ of about $90 \%$ at $37^{\circ} \mathrm{C}$ and $87 \%$ at $42^{\circ} \mathrm{C}(T>$ LCST), respectively. Both temperatures are much higher than the LCST of that star. The effect that the $\mathrm{pH}$ has on the release rate is clearly visible in the case of the star polymer containing 4MBA units.

The kinetics of release depend on the difference between the experimental temperature and the LCST; in other words, they depend on how large this difference is. The slowest release rate was obtained when the experimental temperature was lower than the LCST. In this case, the PHA hydrophobic shell over the core of the star polymer containing $4 \mathrm{MBA}$ units retained $75 \%$ of the 5 -FU loaded. In the case of the star without $4 \mathrm{MBA}$ units, the release temperature was $5^{\circ} \mathrm{C}$ higher than the LCST; the star polymer tends to precipitate generating release channels for 5-FU.

Drug release studies with temperature jump cycles between $37^{\circ} \mathrm{C}$ and $42^{\circ} \mathrm{C}$ are shown in Figure 8 . Increasing the temperature from $37^{\circ} \mathrm{C}$ to $42^{\circ} \mathrm{C}$ results in an increase of release rate for the star without acid units $(T>$ LCST at both temperatures) indicating a temperature effect on drug diffusivity. However, the temperature release control is more efficient for the polymeric star containing the acid monomers when it goes from $T<\mathrm{LCST}$ at $37^{\circ} \mathrm{C}$ and $\mathrm{pH} 7.4$ to $T=\mathrm{LCST}$ at $42^{\circ} \mathrm{C}$ and the same $\mathrm{pH}$.

In this experiment, it was also observed that the star polymer with arms containing acid units (4MBA) acts as a nanopump since the temperature cycles increased the rate of release. Altogether, $100 \%$ drug release was attained after $6.5 \mathrm{~h}$ of applying temperature cycles, whilst at a constant temperature, the cumulative release was $70 \%$ after $26 \mathrm{~h}$ at $42^{\circ} \mathrm{C}(\mathrm{pH} \mathrm{7.4)}$.

At $\mathrm{pH}$ of 6 , faster release than at $\mathrm{pH}$ of 7.4 was observed, both at $37^{\circ} \mathrm{C}$ (Figure 8). A jump in temperature to $42^{\circ} \mathrm{C}$ produces even faster release at both $\mathrm{pH}$ values, delivering the payload in the first temperature cycle almost completely at $\mathrm{pH} 6$ but not at $\mathrm{pH}$ 7.4. These results are very encouraging in regard to the potential application as release carriers of the temperature and $\mathrm{pH}$ sensitive star polymers that were prepared, considering that release occurs at conditions found in some pathologies such as in tumors. Based on these results, the star polymer containing acid units, namely, $\left[\text { poly }\left(\text { NIPAAm-co- } 4 \mathrm{MBA}_{5 \%}\right) \text { - } b \text {-polyHA }\right]_{1}-\mathrm{EGDMA}_{10}\left(M_{n}=\right.$ $100,700 \mathrm{~g} / \mathrm{mol})$, represents an advanced drug carrier exhibiting tunable release kinetics for 5-FU that can be modified by increasing the temperature above the normal body temperature at physiological $\mathrm{pH}$, either by a pathology or by external induction, and/or at lower $\mathrm{pH}$ than physiological $\mathrm{pH}$ in the site of delivery at normal body temperature, as found in tumors or in endosomes.

\section{Conclusions}

It was shown that it is possible to synthetize star polymers with well-defined arms in specific composition by combining 


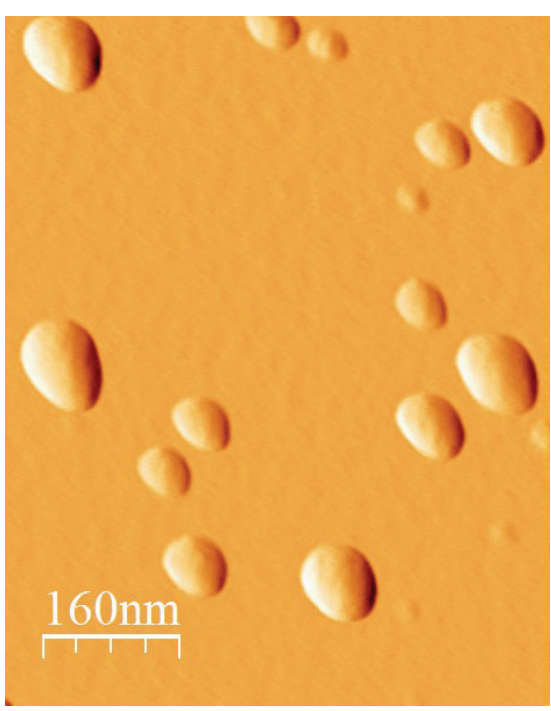

(a)

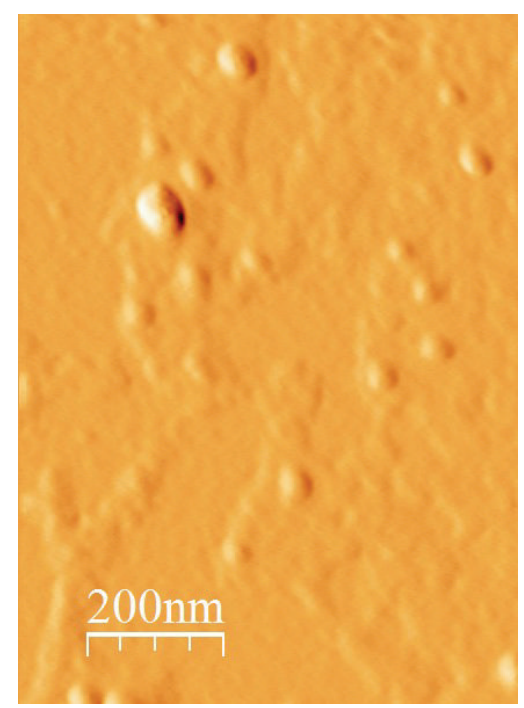

(b)

FIGURE 6: AFM topography images of star polymers: (a) [poly(NIPAAm-co-4MBA $5 \%$ ) $]_{1}-\mathrm{EGDMA}_{10}$, (b) [polyNIPAAm- $b$-polyHA $]_{1}$ EGDMA $_{10}$.

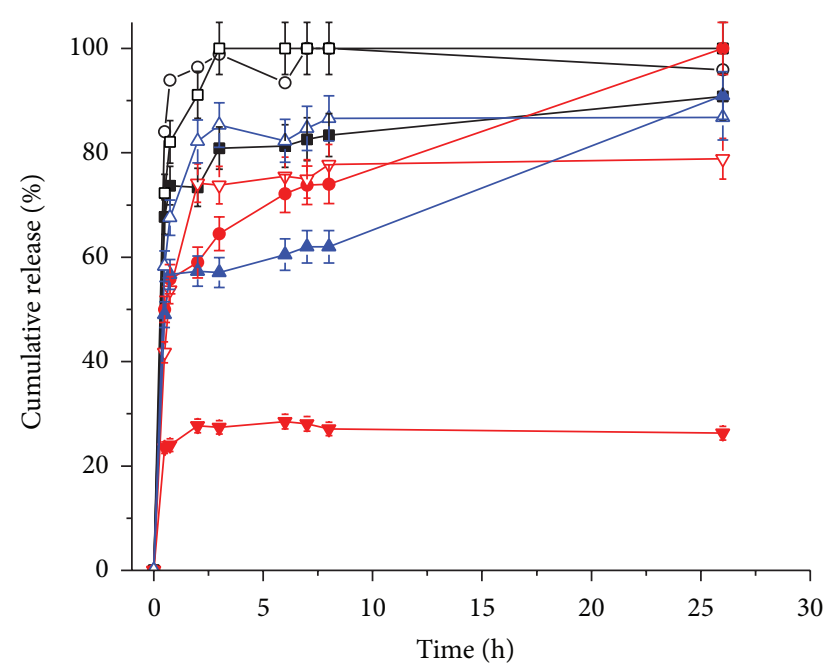

FIGURE 7: Release of 5-fluorouracil from different star polymers at constant temperatures: free 5-fluorouracil in $\mathrm{PBS}$ at $\mathrm{pH} 6$ at $37^{\circ} \mathrm{C}(\mathrm{O})$ and at $\mathrm{pH} 7.4$ at $37^{\circ} \mathrm{C}(\square)$ and at $42^{\circ} \mathrm{C}(\square)$; star polymer [poly(NIPAAm-co-4MBA)-b-polyHA] $]_{1}$ EGDMA $_{10}$ in $\mathrm{PBS}$ at $\mathrm{pH} 6$ at $37^{\circ} \mathrm{C}(\bullet)$ and at $\mathrm{pH} 7.4$ at $37^{\circ} \mathrm{C}(\boldsymbol{\nabla})$ and at $42^{\circ} \mathrm{C}(\nabla)$; star polymer [polyNIPAAm- $b$-polyHA $]_{1}-$ EGDMA $_{10}$ in $\mathrm{PBS}$ at $\mathrm{pH} 7.4$ at $37^{\circ} \mathrm{C}(\boldsymbol{\Delta})$ and $42^{\circ} \mathrm{C}(\triangle)$.

the RAFT technique with the use of cross-linkers. The ratio of cross-linker to macro-CTA (arms) is critical in order to obtain the desired product. The prepared star polymers containing (polyNIPAAm- $b$-polyHA) arms in different sizes and composition with a cross-linked core showed the same LCST as linear polyNIPAAm $\left(30-32^{\circ} \mathrm{C}\right)$. The RAFT process allows for the incorporation of amphiphilic weak acids into the polyNIPAAm block producing $\mathrm{pH}$ and temperature sensitive materials. The LCST of the star polymers containing

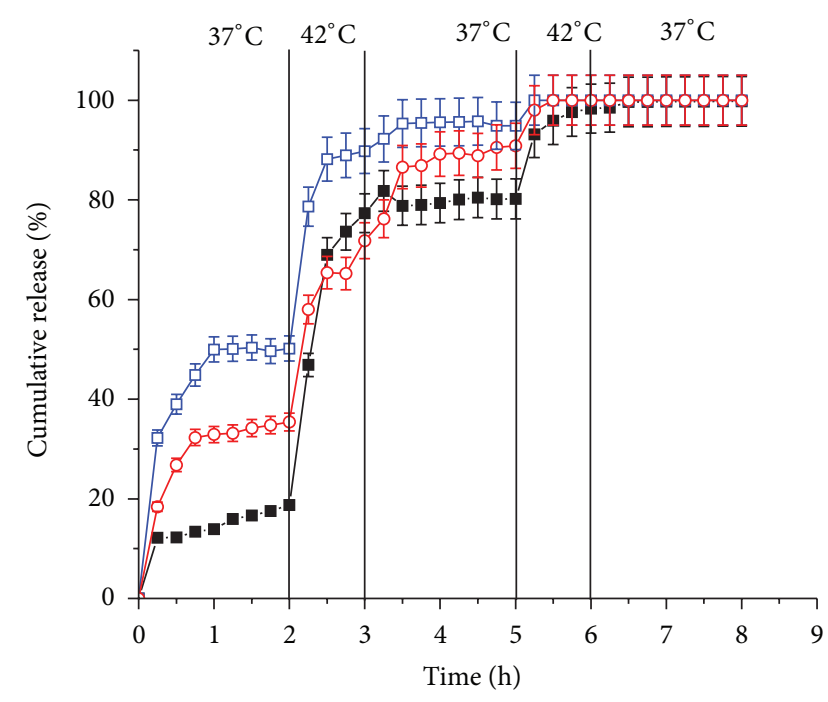

FIgURE 8: Release of 5-fluorouracil from star polymer $\left\{[\text { poly(NIPAAm-co-4MBA)- } b \text {-polyHA }]_{1}-\right.$ EGDMA $\left._{10}\right\}$ in PBS at $\mathrm{pH} 7.4(\square)$ and $\mathrm{PBS}$ at $\mathrm{pH} 6(\square)$ and from star polymer [polyNIPAAm- $b$-polyHA] $]_{1}-$ EGDMA $_{10}$ in PBS at pH 7.4 (O) with temperature jump cycles from 37 to $42^{\circ} \mathrm{C}$.

[poly(NIPAAm-co-4MBA)-b-polyHA] arms was tailored to values in the range of 40 to $46^{\circ} \mathrm{C}$, at $\mathrm{pH}$ of 7.4 , depending on $4 \mathrm{MBA}$ content, and about $36^{\circ} \mathrm{C}$ at $\mathrm{pH}$ of 6 . The polymeric stars can be loaded with 5 -FU up to $30 \mathrm{w} / \mathrm{w} \%$. In vitro release experiments showed that the star polymer materials release 5FU at higher rates when the temperature is above their LCST. The loaded star polymers behave as nanopumps with off/on release if subjected to temperature cycles around the LCST. From these findings, we conclude that the temperature sensitive star polymers with an adjusted LCST, containing 4MBA, 
are promising intelligent drug carriers with the advantages of temperature and $\mathrm{pH}$ adjustable release kinetics.

\section{Conflict of Interests}

The authors declare that there is no conflict of interests regarding the publication of this paper.

\section{Acknowledgments}

This work was supported by the National Council of Science and Technology of Mexico (CONACYT) Grants CB2010C01-157173, CB2012-C01-178709, and INFR2014-C01-224284. Elizabeth Sánchez-Bustos thanks CONACYT for PHD fellowship (no. 208593). Furthermore, the technical support in NMR analysis by I. A. Rivero and A. Ochoa-Terán and in AFM analysis by P. Navarro is gratefully acknowledged. The authors are indebted to L. A. Licea-Higgs for English corrections in the paper.

\section{References}

[1] D. Kuckling and A. Wycisk, "Stimuli-responsive star polymers," Journal of Polymer Science, Part A: Polymer Chemistry, vol. 51, no. 14, pp. 2980-2994, 2013.

[2] M. A. Cohen-Stuart, W. T. S. Huck, J. Genzer et al., "Emerging applications of stimuli-responsive polymer materials," Nature Materials, vol. 9, no. 2, pp. 101-113, 2010.

[3] H. Gao and K. Matyjaszewski, "Synthesis of functional polymers with controlled architecture by CRP of monomers in the presence of cross-linkers: from stars to gels," Progress in Polymer Science, vol. 34, no. 4, pp. 317-350, 2009.

[4] N. Hadjichristidis, M. Pitsikalis, and H. Iatrou, "Polymers with star-related structures," in Macromolecular Engineering: Precise Synthesis, Materials Properties, Applications, K. Matyjaszewski, Y. Gnanou, and L. Leibler, Eds., chapter 6, pp. 909-971, WileyVCH, Weinheim, Germany, 2007.

[5] A. Blencowe, J. F. Tan, T. K. Goh, and G. G. Qiao, "Core crosslinked star polymers via controlled radical polymerisation," Polymer, vol. 50, no. 1, pp. 5-32, 2009.

[6] A. Vora, K. Singh, and D. C. Webster, "A new approach to 3-miktoarm star polymers using a combination of reversible addition-fragmentation chain transfer (RAFT) and ring opening polymerization (ROP) via 'Click' chemistry,' Polymer, vol. 50, no. 13, pp. 2768-2774, 2009.

[7] J.-G. Zilliox, D. Decker, and P. Rempp, "Herstellung von 'Sternpolymeren' auf anionischem Wege," Angewandte Chemie, vol. 78, no. 11, p. 614, 1966.

[8] K. Matyjaszewski and J. Xia, "Atom transfer radical polymerization," Chemical Reviews, vol. 101, no. 9, pp. 2921-2990, 2001.

[9] C. J. Hawker, A. W. Bosman, and E. Harth, "New polymer synthesis by nitroxide mediated living radical polymerizations," Chemical Reviews, vol. 101, no. 12, pp. 3661-3688, 2001.

[10] R. T. A. Mayadunne, J. Jeffery, G. Moad, and E. Rizzardo, "Living free radical polymerization with reversible addition-fragmentation chain transfer (RAFT polymerization): approaches to star polymers," Macromolecules, vol. 36, no. 5, pp. 1505-1513, 2003.

[11] A. B. Lowe and C. L. McCormick, "Reversible addition-fragmentation chain transfer (RAFT) radical polymerization and the synthesis of water-soluble (co)polymers under homogeneous conditions in organic and aqueous media," Progress in Polymer Science, vol. 32, no. 3, pp. 283-351, 2007.

[12] J. Alvarez-Sánchez, A. Licea-Claveríe, J. M. Cornejo-Bravo, and C. W. Frank, "Star polymers with random number of temperature sensitive arms and crosslinked poly(EGDMA)-core and their application to drug delivery," Reactive and Functional Polymers, vol. 71, no. 11, pp. 1077-1088, 2011.

[13] L. A. Picos-Corrales, A. Licea-Claverie, J. M. Cornejo-Bravo, K.F. Arndt, and S. Schwarz, "Well-defined $N$-isopropylacrylamide dual-sensitive copolymers with LCST $\approx 38^{\circ} \mathrm{C}$ in different architectures: linear, block and star polymers," Macromolecular Chemistry and Physics, vol. 213, no. 3, pp. 301-314, 2012.

[14] G. Lapienis, "Star-shaped polymers having PEO arms," Progress in Polymer Science, vol. 34, no. 9, pp. 852-892, 2009.

[15] J. Li, J. Ren, Y. Cao, and W. Yuan, "Synthesis of biodegradable pentaarmed star-block copolymers via an asymmetric BIS-TRIS core by combination of ROP and RAFT: from star architectures to double responsive micelles," Polymer, vol. 51, no. 6, pp. 1301$1310,2010$.

[16] X. Li, Y. Qian, T. Liu et al., "Amphiphilic multiarm star block copolymer-based multifunctional unimolecular micelles for cancer targeted drug delivery and MR imaging," Biomaterials, vol. 32, no. 27, pp. 6595-6605, 2011.

[17] S. Aryal, M. Prabaharan, S. Pilla, and S. Gong, "Biodegradable and biocompatible multi-arm star amphiphilic block copolymer as a carrier for hydrophobic drug delivery," International Journal of Biological Macromolecules, vol. 44, no. 4, pp. 346-352, 2009.

[18] M. L. Adams, A. Lavasanifar, and G. S. Kwon, "Amphiphilic block copolymers for drug delivery," Journal of Pharmaceutical Sciences, vol. 92, no. 7, pp. 1343-1355, 2003.

[19] E. He, C. Y. Yue, and K. C. Tam, "Association behavior of starshaped $\mathrm{pH}$-responsive block copolymer: four-arm poly(ethylene oxide)-b-poly(methacrylic acid) in aqueous medium," Langmuir, vol. 25, no. 9, pp. 4892-4899, 2009.

[20] A. Kowalczuk, B. Trzebicka, S. Rangelov, M. Smet, and A. Dworak, "Star macromolecules with hyperbranched poly(arylene oxindole) cores and polyacid arms: synthesis and solution behavior," Journal of Polymer Science Part A: Polymer Chemistry, vol. 49, no. 23, pp. 5074-5086, 2011.

[21] Q. Bian, Y. Xiao, and M. Lang, "Thermoresponsive biotinylated star amphiphilic block copolymer: synthesis, self-assembly, and specific target recognition," Polymer, vol. 53, no. 8, pp. 16841693, 2012.

[22] H. Kobayashi, R. Watanabe, and P. L. Choyke, "Improving conventional enhanced permeability and retention (EPR) effects; what is the appropriate target?" Theranostics, vol. 4, no. 1, pp. 81-89, 2014.

[23] K. Engin, D. B. Leeper, J. R. Cater, A. J. Thistlethwaite, L. Tupchong, and J. D. Mcfarlane, "Extracellular ph distribution in human tumours," International Journal of Hyperthermia, vol. 11, no. 2, pp. 211-216, 1995.

[24] I. F. Tannock and D. Rotin, "Acid pH in tumors and its potential for therapeutic exploitation," Cancer Research, vol. 49, no. 16, pp. 4373-4384, 1989.

[25] J. C. Garbern, E. Minami, P. S. Stayton, and C. E. Murry, "Delivery of basic fibroblast growth factor with a $\mathrm{pH}$-responsive, injectable hydrogel to improve angiogenesis in infarcted myocardium," Biomaterials, vol. 32, no. 9, pp. 2407-2416, 2011.

[26] A. M. Ponce, Z. Vujaskovic, F. Yuan, D. Needham, and M. W. Dewhirst, "Hyperthermia mediated liposomal drug delivery," 
International Journal of Hyperthermia, vol. 22, no. 3, pp. 205213, 2006

[27] W. Xiong, W. Wang, Y. Wang et al., "Dual temperature/pHsensitive drug delivery of poly( $\mathrm{N}$-isopropylacrylamide-coacrylic acid) nanogels conjugated with doxorubicin for potential application in tumor hyperthermia therapy," Colloids and Surfaces B: Biointerfaces, vol. 84, no. 2, pp. 447-453, 2011.

[28] A. Chilkotia, M. R. Drehera, D. E. Meyera, and D. Raucherb, "Targeted drug delivery by thermally responsive polymers," Advanced Drug Delivery Reviews, vol. 54, no. 5, pp. 613-630, 2002.

[29] J. E. Chung, M. Yokoyama, M. Yamato, T. Aoyagi, Y. Sakurai, and T. Okano, "Thermo-responsive drug delivery from polymeric micelles constructed using block copolymers of poly( $N$-isopropylacrylamide) and poly(butylmethacrylate)," Journal of Controlled Release, vol. 62, no. 1-2, pp. 115-127, 1999.

[30] L. Zhang, G. Rui, Y. Mi, J. Xiqun, and L. Baorui, “Thermo and $\mathrm{pH}$ dual-responsive nanoparticles for anti-cancer drug delivery," Advanced Materials, vol. 19, no. 19, pp. 2988-2992, 2007.

[31] F. M. Winnik, A. R. Davidson, G. K. Hamer, and H. Kitano, "Amphiphilic poly(N-isopropylacrylamides) prepared by using a lipophilic radical initiator: synthesis and solution properties in water," Macromolecules, vol. 25, no. 7, pp. 1876-1880, 1992.

[32] M. A. Ward and T. K. Georgiou, "Thermoresponsive polymers for biomedical applications," Polymers, vol. 3, no. 3, pp. 12151242, 2011.

[33] L. Klouda and A. G. Mikos, "Thermoresponsive hydrogels in biomedical applications," European Journal of Pharmaceutics and Biopharmaceutics, vol. 68, no. 1, pp. 34-45, 2008.

[34] A. Serrano-Medina, J. M. Cornejo-Bravo, and A. LiceaClaveríe, "Synthesis of $\mathrm{pH}$ and temperature sensitive, core-shell nano/microgels, by one pot, soap-free emulsion polymerization," Journal of Colloid and Interface Science, vol. 369, no. 1, pp. 82-90, 2012.

[35] C. Obeso-Vera, J. M. Cornejo-Bravo, A. Serrano-Medina, and A. Licea-Claverie, "Effect of crosslinkers on size and temperature sensitivity of poly(N-isopropylacrylamide) microgels," Polymer Bulletin, vol. 70, no. 2, pp. 653-664, 2013.

[36] W.-Q. Chen, H. Wei, S.-L. Li et al., "Fabrication of starshaped, thermo-sensitive poly(N-isopropylacrylamide)-cholic acid-poly( $\varepsilon$-caprolactone) copolymers and their self-assembled micelles as drug carriers," Polymer, vol. 49, no. 18, pp. 39653972, 2008.

[37] H. Wei, W.-Q. Chen, C. Chang et al., "Synthesis of star block, thermosensitive poly(L-lactide)-star block-poly( $N$-isopropylacrylamide-co- $N$-hydroxymethylacrylamide) copolymers and their self-assembled micelles for controlled release," The Journal of Physical Chemistry C, vol. 112, no. 8, pp. 2888-2894, 2008.

[38] S. J. T. Rezaei, M. R. Nabid, H. Niknejad, and A. A. Entezami, "Folate-decorated thermoresponsive micelles based on starshaped amphiphilic block copolymers for efficient intracellular release of anticancer drugs," International Journal of Pharmaceutics, vol. 437, no. 1-2, pp. 70-79, 2012.

[39] K. Miao, H. Liu, and Y. Zhao, "Thermo, $\mathrm{pH}$ and reduction responsive coaggregates comprising $\mathrm{AB}_{2} \mathrm{C}_{2}$ star terpolymers for multi-triggered release of doxorubicin," Polymer Chemistry, vol. 5, no. 10, pp. 3335-3345, 2014.

[40] L. Saleh-Ghadimi, M. Fathi, and A. A. Entezami, "Heteroarm star-shaped poly ( $N$-isopropylacryamide-co-itaconic acid) copolymer prepared by glucose core as ATRP initiator,"
International Journal of Polymeric Materials and Polymeric Biomaterials, vol. 63, no. 5, pp. 246-255, 2014.

[41] F. Xu, J.-W. Xu, B.-X. Zhang, and Y.-L. Luo, "Self-assembly micelles from novel tri-armed star C3-(PS-b-PNIPAM) block copolymers for anticancer drug release," AIChE Journal, vol. 61, no. 1, pp. 35-45, 2015.

[42] S.-P. Rwei, Y.-Y. Chuang, T.-F. Way, W.-Y. Chiang, and S.-P. Hsu, "Preparation of thermo- and $\mathrm{pH}$-responsive star copolymers via ATRP and its use in drug release application," Colloid and Polymer Science, vol. 293, no. 2, pp. 493-503, 2015.

[43] Q. Chen, X. Cao, Y. Xu, and Z. An, "Emerging synthetic strategies for core cross-linked star (CCS) polymers and applications as interfacial stabilizers: bridging linear polymers and nanoparticles," Macromolecular Rapid Communications, vol. 34, no. 19, pp. 1507-1517, 2013.

[44] J. Ferreira, J. Syrett, M. Whittaker, D. Haddleton, T. P. Davis, and C. Boyer, "Optimizing the generation of narrow polydispersity 'arm-first' star polymers made using RAFT polymerization," Polymer Chemistry, vol. 2, no. 8, pp. 1671-1677, 2011.

[45] J. Liu, H. Duong, M. R. Whittaker, T. P. Davis, and C. Boyer, "Synthesis of functional core, star polymers via RAFT polymerization for drug delivery applications," Macromolecular Rapid Communications, vol. 33, no. 9, pp. 760-766, 2012.

[46] R. Salgado-Rodríguez, A. Licea-Claveríe, and K.-F. Arndt, "Random copolymers of $\mathrm{N}$-isopropylacrylamide and methacrylic acid monomers with hydrophobic spacers: $\mathrm{pH}$-tunable temperature sensitive materials," European Polymer Journal, vol. 40, no. 8, pp. 1931-1946, 2004.

[47] J. Brandrup, E. H. Immergut, and E. A. Grulke, Eds., Polymer Handbook, John Wiley \& Sons, New York, NY, USA, 4th edition, 1999.

[48] K.-F. Arndt and G. Müller, Polymer Charakterisierung, Carl Hanser, München, Germany, 1996.

[49] A. Licea-Claveríe, E. Rogel-Hernández, J. A. Lopéz-Sanchez, L. A. Castillo-Arambula, J. M. Cornejo-Bravo, and K. F. Arndt, "A facile synthesis route for carboxyaryl-methacrylates; a way to obtain aromatic polyelectrolytes," Designed Monomers and Polymers, vol. 6, no. 1, pp. 67-80, 2003. 

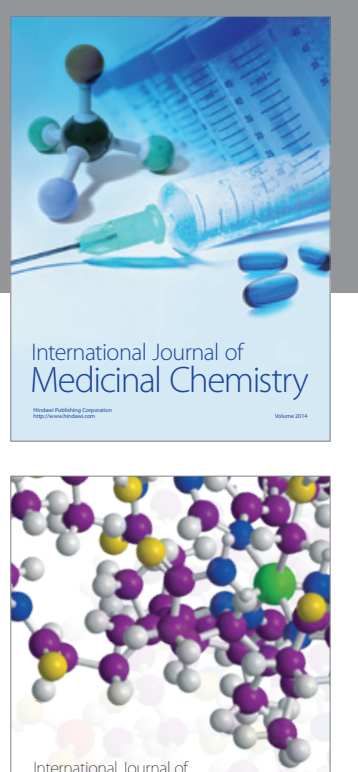

Carbohydrate Chemistry

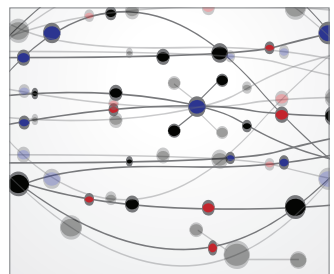

The Scientific World Journal
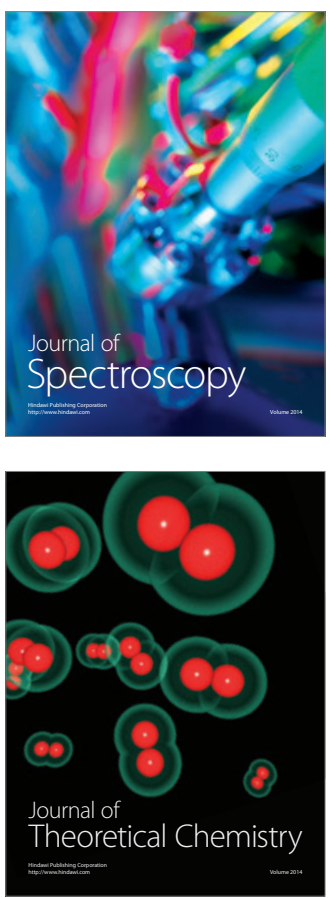
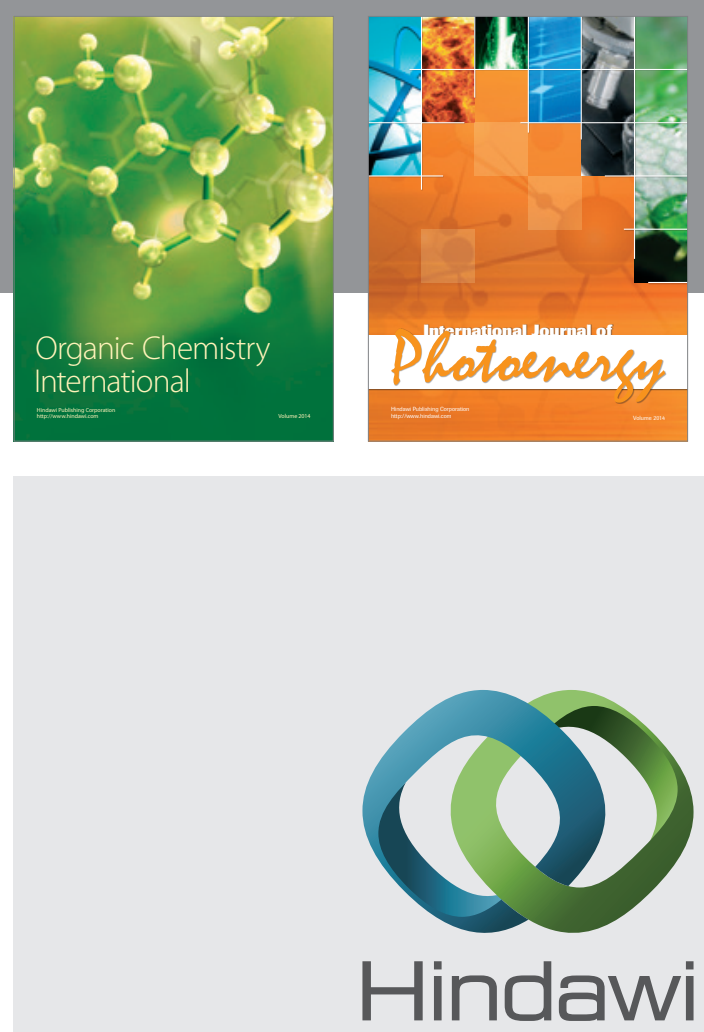

Submit your manuscripts at

http://www.hindawi.com

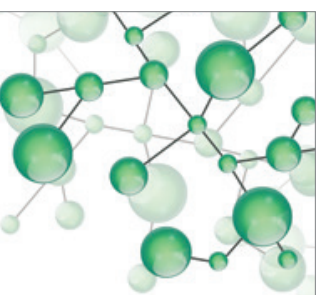

International Journal of

Inorganic Chemistry

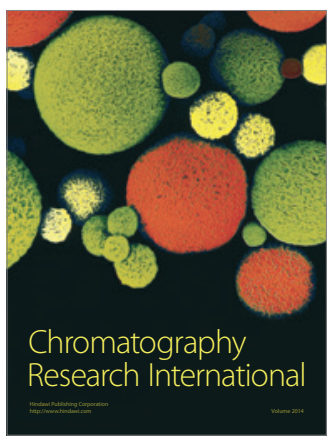

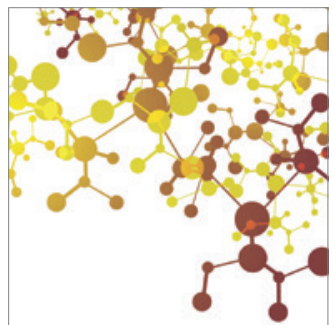

Applied Chemistry
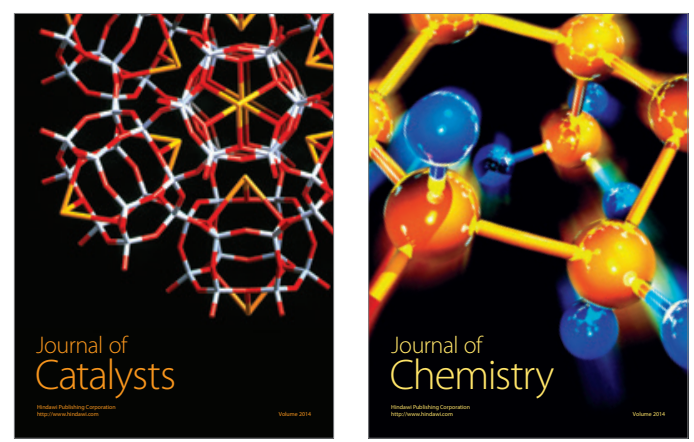
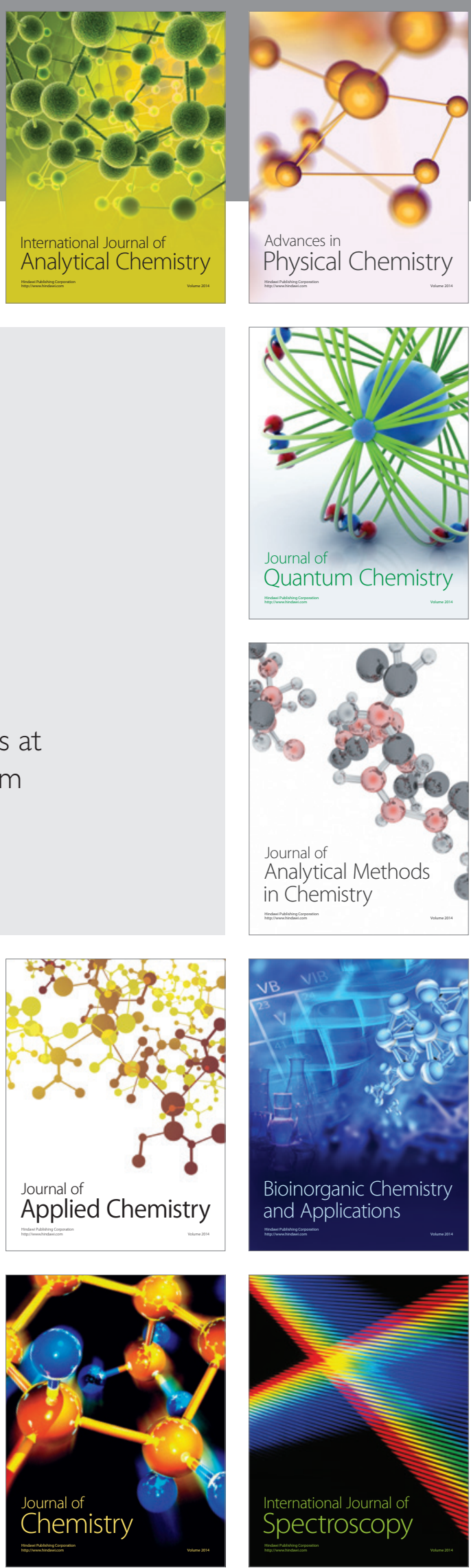